\title{
Letter to the Editor: Management of Locally Advanced and Unresectable Small Bowel Neuroendocrine Tumours
}

\author{
D. S. V. M. Clement ${ }^{1}$ R. Srirajaskanthan ${ }^{1}$
}

Accepted: 15 February 2021 / Published online: 17 March 2021

(C) Société Internationale de Chirurgie 2021

We read with great interest the recent work by Koea and colleagues on behalf of the commonwealth neuroendocrine tumour (NET) research collaborative. The article clearly highlights a surgical approach to the complex problem of unresectable small bowel NETs. They clearly stratify the three subtypes of small bowel NETs and also the surgical approach that can be considered [1]. We thought it would be useful to point the role of palliative total parental nutrition (TPN) in selected patients. The role of palliative TPN in patients with NETs is not well established; however, there are small case series and we have previously published data on the role TPN in improving survival and quality of life in patients with persistent small bowel obstruction or short bowel syndrome secondary to NET resection [2-5]. In 2005 Hoda et al. performed a retrospective study on 52 patients with incurable cancer on home care TPN; 10 patients had a primary carcinoid tumour. After 1 year $50 \%$ of carcinoid patients were still alive on TPN, 1 patient survived for 154 months on TPN. Main reasons for starting TPN in this group were malabsorption/short bowel syndrome (4 patients) and 1 patient with bowel obstruction [2]. In 2020, Sagar and colleagues published a retrospective study on 8 NET patients with a median period on TPN for 12.4 months. In this group, short bowel syndrome was present in 50\% of patients and $25 \%$ of patients had bowel obstruction. The quality of life score of these patients improved after initiation of TPN, with low rates of catheter related bloodstream infections [4]. Our group has previously published regarding 30 NET patients from the UK and the Netherlands on TPN. The median

D. S. V. M. Clement

dominique.clement@nhs.net

1 Neuroendocrine Tumours Unit, King's College Hospital NHS Foundation Trust, London, UK survival was 12 months; main indications for TPN were short bowel syndrome $(70 \%)$ and inoperable small bowel obstruction (27\%). Three patients from this cohort were still alive on TPN after 50 months [5].

In selected cases of patients where bypass leads to difficulty maintaining nutrition then TPN could be considered and also in patients where surgery if declined due to concerns regarding short bowel syndrome there is a potential role TPN to maintain nutritional status as part of palliative care.

\section{References}

1. Koea J, Hallett J, Law C et al (2021) Management of locally advanced and unresectable small bowel neuroendocrine tumours. World J Surg 45:219-224. https://doi.org/10.1007/s00268-02005740-7

2. Hoda D, Jatoi A, Burnes J et al (2005) Should patients with advanced, incurable cancers ever be sent home with total parenteral nutrition? Cancer 103:863-868. https://doi.org/10. $1002 /$ cncr.20824

3. Liu M, Laskaratos F-M, Bennell J et al (2020) Home total parenteral nutrition for intestinal failure in patients with advanced small intestinal neuroendocrine neoplasms. Nutr Cancer. https:// doi.org/10.1080/01635581.2020.1810713

4. Sagar VM, Shah T, Malhi H et al (2020) Home parenteral nutrition in neuroendocrine tumour intestinal failure: improved quality of life and longevity. BMJ Support Palliat Care. https://doi.org/10. 1136/bmjspcare-2020-002562

5. Clement DSVM, Naghibi M, Khan M, Tesselaar MET, Verbeek WHM, Wanten G, Ramage JK, Srirajaskanthan R (2020) The use of total parenteral nutrition in a series of patients with neuroendocrine tumours in United Kingdom and the Netherlands. Neuroendocrinology 110(Suppl 1):1-312

Publisher's Note Springer Nature remains neutral with regard to jurisdictional claims in published maps and institutional affiliations. 